\title{
Research on the Current Situation of Internal Audit Outsourcing Service
}

\author{
Qi Zhou', Bowen $\mathrm{Li}^{2}$, Junwei $\mathrm{Sun}^{3}$ and Muyang $\mathrm{Li}^{4}$ \\ ${ }^{1}$ School of accounting, Anhui University of Finance and Economics, Bengbu, Anhui, China \\ ${ }^{2}$ School of statistics and applied mathematics, Anhui University of Finance and Economics, Bengbu, Anhui, China \\ ${ }^{3}$ School of statistics and applied mathematics, Anhui University of Finance and Economics, Bengbu, Anhui, China \\ ${ }^{4}$ School of accounting, Anhui University of Finance and Economics, Bengbu, Anhui, China
}

\begin{abstract}
Under the background of the rapid development of market economy, the competitive pressure among enterprises is growing day by day. In the continuous practice and exploration, enterprises realize the importance of internal audit. However, due to the fierce competition and the inherent defects of internal audit, more and more enterprises adopt the form of outsourcing for internal audit. However, there are still many problems because the internal audit outsourcing is in the initial stage. Therefore, this paper will theoretically analyze the advantages and risks of internal audit in all aspects, and put forward suggestions according to the analysis results.
\end{abstract}

Keywords: Internal audit, Outsourcing, Current situation analysis.

\section{Introduction}

As a necessary means for enterprises to improve their governance structure, optimize their capital structure and achieve their strategic objectives, more and more enterprises begin to realize the importance of internal audit. Due to the increasingly tense economic situation, the competitive environment faced by enterprises is also deteriorating. However, enterprises need to continuously develop and expand their business scale. At the same time, internal audit has inherent defects. Therefore, many enterprises in the market begin to seek help from outsourcing institutions in order to better control risks and implement management measures within the enterprise.

Internal audit and external audit are different in many aspects. Internal audit has higher requirements for professional knowledge and audit standards. Therefore, internal audit outsourcing in the market refers to that an enterprise entrusts all or part of its internal audit business to external contractors in the form of paying for internal audit services by purchasing internal audit services, so as to obtain professional audit resources and solve internal management problems [1]. In a word, internal audit outsourcing can better meet the requirements of enterprise management and other management personnel for mastering enterprise information quality.

However, because China's accounting is introduced from the west, there are many problems, such as defects and imperfect system. As a branch of accounting, audit is more imperfect, so the outsourcing service of internal audit is far from universal. At present, the problem of internal audit outsourcing service in China is the contradiction between the increasing competitive pressure and the shortage of internal audit outsourcing service.

\section{The defects of enterprise internal audit and the necessity of outsourcing services}

\subsection{Defects of Enterprise Internal Audit}

Since the reform and opening up, China's economic growth has made rapid progress and achieved remarkable results. Economic growth is inseparable from the rapid development of domestic enterprises. Enterprises also continue to develop and grow because of the rapid economic development, which also leads to the emergence of more and more excellent enterprises, and even monopoly in some industries, which makes the living environment of small and medium-sized enterprises in the market more difficult. For enterprises, if they want to develop and grow in the difficult market production environment, they need to conduct internal audit on all aspects of the enterprise from time to time, so that the management can comprehensively consider all aspects of the enterprise. However, due to the late start of the development of internal audit in China and the late start of market economy as compared with the west, most enterprises in the market pay less attention to the construction of internal audit team. At the same time, the internal audit institutions of enterprises are generally established by independent and non-executive chairmen, and most of them lack rich financial background, The level of understanding of the professional knowledge of internal audit cannot be comparable to that of professional internal auditors. Therefore, the neglect of the enterprise and the composition and construction of internal audit make the enterprise's internal audit team lack of enough excellent internal auditors, which further leads to the management at all levels of the enterprise unable to deeply understand the problems of the enterprise and solve the problems in enterprise management in time, which is easy to make the enterprise fall into risk.

\subsection{Necessity of Outsourcing Internal Audit Services}

For large enterprises, when the business scale of the 
enterprise develops to a certain extent, if the enterprise wants to be successfully listed on the exchange, it must audit the IPO project for a long time by purchasing internal audit outsourcing services. However, the enterprise's negligence in the construction of internal audit team makes it unable to be competent for audit projects because of the lack of enough excellent internal auditors, which requires the enterprise to seek external forces and hire professionals for professional internal audit. Among them, the accounting firm is the gathering place of professional internal auditors, with a professional team and rich internal audit experience, which can provide internal audit services for the enterprise. The professional internal audit team can find the existing risk events in the business process through previous experience, and put forward relevant risk control measures and management control measures through analysis, Make the enterprise's internal audit achieve a qualitative leap in efficiency and quality.

For small and medium-sized enterprises, the establishment of an independent internal audit institution means that enterprises need to pay a series of expenses for this institution, such as venue fees, training fees and the salary of internal auditors. In addition, the internal audit will also change with the changes of the internal and external environment of the enterprise, making the internal auditors incompetent, resulting in the problems of low work quality and low work efficiency in the internal audit, which directly affects the reasonable judgment of the management to a certain extent and solve the problems in the enterprise in time. If an enterprise chooses to cooperate with an accounting firm, purchase the internal audit services provided by it and realize internal audit outsourcing, it will not only save the enterprise excess expenditure and reduce the audit cost, but also enable the enterprise to more comprehensively understand the remaining risk problems of the enterprise, which will help the enterprise to realize effective management at an appropriate cost.

In addition, most of the internal auditors in the enterprise enter the enterprise through the human resources policy channels of the enterprise. As employees of enterprises, it is inevitable that they will make internal audit reports in violation of audit standards due to the wishes of superior leaders, which makes the results of internal audit not true and accurate. The auditors in the intermediary institutions not only have high professional quality, but also do not form a labor contract relationship with the enterprise. Therefore, auditing the enterprise in the form of internal audit outsourcing will weaken the influence of this factor and provide a strong guarantee for obtaining more objective audit results.

\section{Remaining Problems of Internal Audit Outsourcing Services}

\subsection{The Quality of Internal Audit Reports Is Uneven}

At present, in terms of the outsourcing service environment of enterprise internal audit in China, it has become a common phenomenon for enterprises to hire accounting firms to carry out enterprise internal audit. The accounting industry has gradually become saturated after years of development. In the saturated talent market, the competitive pressure of accounting firms is becoming increasingly fierce. Each accounting firm is scrambling to expand its business and the business volume is also increasing. Therefore, after receiving the outsourcing business from enterprises, many accounting firms may be busy, but rush to provide audit reports to enterprises. This will lead to differences in the quality of internal audit reports, bring hidden risks to enterprises and destroy the independence of audit business [5].

\subsection{Information Distortion and Asymmetric Risk}

Because the enterprise does not have a long-term employment relationship with the auditors in the intermediary institutions, the internal audit services provided by the intermediary institutions lose flexibility and initiative. Although the auditors employed have higher professional and technical ability and richer industry experience, because they are not long-term employees of the enterprise, the auditors' understanding of the real situation inside the enterprise is not high enough, resulting in asymmetric audit information and easy distortion. In addition, most of the outsourcing auditors only do their own work, and can't do their best like the internal auditors, only audit the whole company. Therefore, outsourcing auditors may miss audit. Once there are problems such as missing audit and wrong audit, it will be detrimental to the future development of the company [5].

\subsection{Risk of Trade Secret Disclosure}

When enterprises employ outsourcing auditors, if they do not take appropriate measures to manage and balance the work of outsourcing auditors, they will face the risk of disclosure of trade secrets in the process of outsourcing auditors' work. At the same time, China's current requirements on the confidentiality of internal audit outsourcing have not been constrained by legal provisions, and the supervision of relevant industries is not strong enough These reasons make it easy for enterprises to disclose their business secrets when hiring outsourcing auditors for internal audit. As the core of the enterprise's competition, once the trade secret is published to the public, the enterprise will face huge losses and is likely to lose the competitiveness of the enterprise in its industry.

\section{Suggestions on Outsourcing Internal Audit Services}

\subsection{Strengthen the Management of Internal Audit}

In order to ensure the quality and efficiency of internal audit outsourcing services and the confidentiality of internal audit outsourcing services, enterprises should provide corresponding training for managers, and maintain the principle of prudence when signing contracts with accounting firms. Specific measures are as follows.

\subsubsection{Regularly Train Enterprise Managers}

In order to achieve the long-term development strategic objectives of the enterprise, the corresponding control objectives of the enterprise need to be consistent with the enterprise development strategic objectives. The implementation of control objectives is inseparable from the supervision of enterprise managers. Therefore, enterprises can increase investment in training the quality of managers, so that enterprise managers can better take appropriate measures for enterprise development strategies. At the same time, it can also lay a foundation for enterprise managers to 
choose the correct form and type of internal audit outsourcing.

\subsubsection{Improve the Contract Management Mechanism}

One of the common risk control measures of enterprises is contract management control. When selecting internal audit outsourcing institutions, enterprises should select intermediaries with good reputation and high service quality, and maintain the principle of prudence when signing contracts, reach an agreement with intermediaries in all aspects, especially trade secrets, and strengthen the supervision of audit work.

\subsubsection{Establishment of Relevant Legal Provisions}

At present, China is in the development stage, and all types of enterprises still need a long time to develop. Nowadays, the competitive environment of Chinese enterprises is becoming increasingly fierce. When enterprises need to expand their business scope to a certain extent, they generally need to issue corresponding audit reports. Most enterprises will choose to hire intermediaries to issue audit reports for enterprises, and the demand for internal audit outsourcing services is growing.
Due to the influence of various factors, there are various risks in internal audit outsourcing services. It is very necessary to establish relevant legal provisions to restrict and standardize the audit process of internal audit outsourcing services.

\section{References}

[1] Cao Jie. Research on internal audit outsourcing [J]. China Agricultural Accounting, 2021 (11): 82-84

[2] Chen Huicong, Fu ran. Analysis of internal audit outsourcing [J]. Cooperative economy and technology, 2021 (14): 156-157.

[3] Wang Chen. Research on the utilization of internal audit results from the perspective of social audit [J]. Hebei enterprises, 2021 (11): 68-71.

[4] Pei Mingzhu. Analysis on risk and avoidance of enterprise internal audit outsourcing [J]. Mall modernization, 2015 (25): 154-155.

[5] Liu Yinglong. Research on forms and existing problems of enterprise internal audit outsourcing [J]. China management informatization, 2021,24 (12): 50-51. 